\title{
Reduction of fibroproliferative changes in irradiated rat lung with soluble transforming growth factor- $\beta$ receptor
}

\author{
AKIHITO NISHIOKA $^{1}$, YASUHIRO OGAWA ${ }^{1}$, SHINJI KARIYA ${ }^{1}$, NORIHIKO HAMADA ${ }^{1}$, \\ MUNENOBU NOGAMI $^{1}$, TAISUKE INOMATA ${ }^{2}$ and HIKARU UENO ${ }^{3}$ \\ ${ }^{1}$ Department of Diagnostic Radiology and Radiation Oncology, Kochi University, School of Medicine, Nankoku, \\ Kochi 783-8505; ${ }^{2}$ Department of Radiation Oncology, Shimane University, Izumo, Shimane 693-8501; \\ ${ }^{3}$ Department of Biochemistry and Molecular Pathophysiology, University of Occupational and \\ Environmental Health, School of Medicine, Kitakyusyu, Fukuoka 807-8556, Japan
}

Received November 25, 2013; Accepted June 9, 2014

DOI: $10.3892 / \mathrm{mmr} .2014 .3064$

\begin{abstract}
The present study investigated whether established fibroproliferative changes in the irradiated rat lung are histopathologically reduced by an adenovirus-mediated soluble transforming growth factor (TGF)- $\beta$ type II receptor. Replication-defective adenoviral vectors expressing a type II human TGF- $\beta$ receptor (AdT $\beta$-ExR) were prepared. Male Fisher-344 rats were divided into the $\mathrm{C}, \mathrm{R}$ and $\mathrm{R}+\mathrm{T}$ groups. The rats in the $\mathrm{C}$ group did not receive irradiation or treatment. The rats in the $\mathrm{R}$ and $\mathrm{R}+\mathrm{T}$ group each received $30 \mathrm{~Gy}$ irradiation to the right lung. Eight weeks following irradiation, the rats in the $\mathrm{R}$ and $\mathrm{R}+\mathrm{T}$ group were treated with saline or AdT $\beta$-ExR, respectively. To analyze the TGF- $\beta$ expression, myofibroblast proliferation and macrophage/monocyte infiltration, sections of the lung were immunohistochemically stained at 16 weeks following irradiation. Silver staining was performed for semi-quantitative evaluation of the fibroproliferative changes. Definitive TGF- $\beta$ expression, myofibroblast proliferation and macrophage/monocyte infiltration were observed in the lungs of the R group, but were significantly lower in the lungs of the $\mathrm{R}+\mathrm{T}$ group. With respect to the fibroproliferative changes, the proportion of red-stained areas in the $\mathrm{R}+\mathrm{T}$ group was markedly lower than that in the $\mathrm{R}$ group. These data indicate that fibroproliferative changes induced by radiation are reversible and that TGF- $\beta$ has a critical role in fibroproliferative changes in the irradiated lung. The present results suggest that gene therapy with an adenoviral vector expressing a soluble TGF- $\beta$ receptor may be effective in reducing the established pulmonary fibrosis caused by radiation.
\end{abstract}

Correspondence to: Dr Akihito Nishioka, Department of Diagnostic Radiology and Radiation Oncology, Kochi University, School of Medicine, Kohasu, Okoh-cho, Nankoku-shi, Kochi 783-8505, Japan

E-mail: nishiokaa@kochi-u.ac.jp

Key words: transforming growth factor- $\beta$, adenoviral vector, radiation-induced pulmonary injury, gene therapy

\section{Introduction}

Radiation-induced pulmonary injuries are important complications of chest irradiation. Clarifying the detailed molecular mechanisms underlying these injuries, and developing effective methods for their prevention and treatment are required for more effective and safer chest irradiation. Fibroproliferative changes resulting in fibrosis are considered to dynamic and reversible processes involving constant remodeling and long-term fibroblast activation. Fibroproliferative lesions contain infiltrating inflammatory cells, including macrophages/monocytes and specific fibroblasts termed myofibroblasts (1-3).

Transforming growth factor- $\beta$ (TGF- $\beta$ ) is considered to be a master switch for fibroproliferative changes in irradiated lung tissue (4-6). That is, overexpression or activation of TGF- $\beta$ for a prolonged period may induce myofibroblast proliferation, macrophage/monocyte infiltration and extracellular matrix deposition, resulting in pulmonary fibrosis (Fig. 1).

Previously, based on the known molecular mechanisms, the ability of adenovirus-mediated soluble TGF- $\beta$ type II receptor gene therapy to ameliorate active TGF- $\beta$ expression and prevent radiation-induced pulmonary injury was demonstrated (7). As the next step, using an adenovirus-mediated soluble TGF- $\beta$ type II receptor, which adsorbs TGF- $\beta$ and may act as a dominant-negative receptor to inhibit the function of wild-type receptor, the present study investigated whether established fibroproliferative changes in the irradiated lung may be reduced.

\section{Materials and methods}

Adenoviral vectors. Replication-defective E1 ${ }^{-}$and E3- adenoviral vectors expressing the entire extracellular domain of the type II human TGF- $\beta$ receptor fused with the Fc protein of human $\operatorname{IgG}_{1}$ (AdT $\beta$-ExR), under the control of a CA promoter comprising a cytomegalovirus enhancer and a chicken $\beta$-actin promoter, was prepared by in vitro homologous recombination in 293 cells (Kyushu University, Fukuoka, Japan), as described previously $(8,9)$. It was confirmed that the soluble TGF- $\beta$ type II receptor was secreted from AdT $\beta$-ExR-infected cells and was detectable in circulating blood following AdT $\beta$-ExR 
injection. It was also confirmed that the soluble receptor bound to TGF- $\beta$ and inhibited TGF- $\beta$ activity in vivo and in vitro $(8,9)$. The titer of the virus stock was assessed by a plaque formation assay using 293 cells and is expressed in plaque-forming units (PFU).

Animal model. The present study was conducted under the Guidelines for Animal Experiments of Kochi University, (Kochi, Japan). All of the animals were treated following the procedures approved by the Committee on Animal Research of Kochi University. Male Fisher-344 rats (SLC, Shizuoka, Japan) aged 12 weeks were divided into three groups: An intact control group (C group), a radiation plus saline group ( $\mathrm{R}$ group) and a radiation plus soluble TGF- $\beta$ type II receptor group ( $\mathrm{R}+\mathrm{T}$ group). Each group consisted of three rats. The rats in the $\mathrm{C}$ group did not receive irradiation or treatment. The rats in the $\mathrm{R}$ and $\mathrm{R}+\mathrm{T}$ groups each received 4-MV X-ray irradiation at a dose of $30 \mathrm{~Gy}$ in a single fraction of the right lung using a linear accelerator (ML-15MDX; Mitsubishi Electric Co., Ltd., Tokyo, Japan). Eight weeks following irradiation, the rats in the $\mathrm{R}$ and $\mathrm{R}+\mathrm{T}$ groups were treated with a single infusion of $0.5 \mathrm{ml}$ saline or AdT $\beta$-ExR $\left(1.0 \times 10^{9}\right.$ $\mathrm{PFU} / \mathrm{ml})$, respectively, via the external jugular vein. It was previously reported that marked TGF- $\beta$ expression, myofibroblast proliferation, macrophage/monocyte infiltration and fibroproliferative changes were observed in the irradiated lungs of rats at 8 weeks following $30 \mathrm{~Gy}$ irradiation (7). The rats in all of the groups were housed under the same conditions with ad libitum access to food and water for 16 weeks after irradiation ( 8 weeks after single infusion). The rats were then sacrificed with an intraperitoneal injection of pentobarbital sodium $(2.5 \mathrm{ml} / \mathrm{rat})$ for lung extraction.

Histopathological examination. For the histopathological investigation, the right lungs of all of the rats were fixed in $10 \%$ neutral-buffered formalin, embedded in paraffin and sectioned (5- $\mu \mathrm{m}$ sections) with a microtome. A number of mounted sections were stained with hematoxylin and eosin (H\&E). To analyze TGF- $\beta$ expression, myofibroblast proliferation and macrophage/monocyte infiltration, other tissue sections of the lung were immunohistochemically stained using the avidin-biotin-horseradish peroxidase complex (ABC) method with anti-TGF- $\beta 1$ antibody (1:100; Promega Corporation, Madison, WI, USA), anti- $\alpha$-smooth muscle actin antibody (1:200; DAKO A/S, Copenhagen, Denmark) and anti-CD68 antibody (1:100; KP1 clone; DAKO A/S) as the primary antibodies. Immunoreactive materials were visualized using biotinylated anti-mouse (or anti-rabbit) immunoglobulin $\mathrm{G}$ secondary antibody (1:100; Vector Laboratories, Inc., CA, USA), peroxidase-labeled streptavidin (Vector Laboratories, Inc.) and diaminobenzidine (Sigma-Aldrich, St. Louis, MO, USA). Firstly, the sections were incubated in the primary antibodies at the appropriate dilutions for $1 \mathrm{~h}$ at room temperature. They were then incubated in peroxidase blocking solution $\left(0.3 \% \mathrm{H}_{2} \mathrm{O}_{2}\right)$ for $10 \mathrm{~min}$ and in the biotinylated secondary antibody for $30 \mathrm{~min}$ at room temperature. Finally, the sections were incubated in peroxidase-labeled streptavidin for $30 \mathrm{~min}$ at room temperature, and then visualized with diaminobenzidine. The number of TGF- $\beta$-expressing cells within a field at a magnification of $\mathrm{x} 400$ (area, $240 \times 320 \mu \mathrm{m}$ ) were then

\section{radiation $\longrightarrow$ lung tissue \\ II}

myofibroblast \& macrophage/monocyte

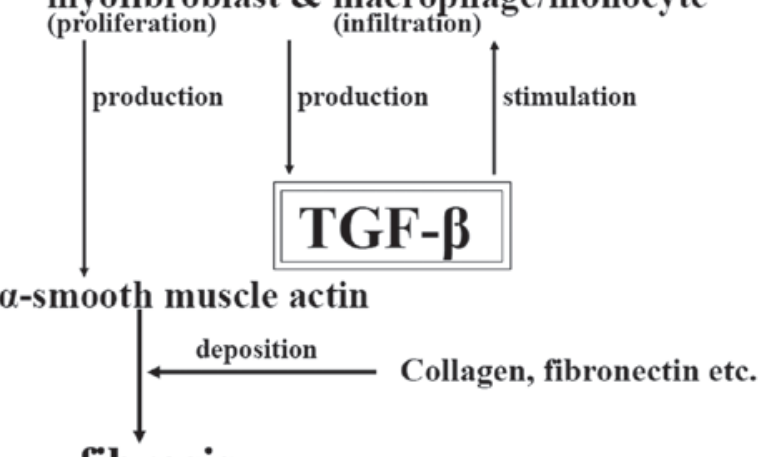

fibrosis

Figure 1. Mechanisms of fibrosis in irradiated lung tissue. TGF- $\beta$, transforming growth factor- $\beta$.

counted using a microscope (Eclipse 80i; Nikon Corporation, Tokyo, Japan). Five fields were randomly selected for each rat and three rats from each group were examined; therefore, a total of 15 fields were analyzed for each group. Proliferating myofibroblasts or infiltrating macrophages/monocytes were also counted using the same method. Silver staining was performed for semi-quantitative evaluation of fibroproliferative changes. The red-stained area in the silver-stained sections was exhibited on a charge-coupled device (CCD)-camera screen (magnification, x400; Keyence Corp., Osaka, Japan), and the percentage of red-stained area in each field (area, $\sim 240 \mathrm{x} 320 \mu \mathrm{m}$ ) was calculated using image analyzing software (Lumina Vision and Mac Scope, Mitani Co., Ltd., Tokyo, Japan).

Statistical analysis. A total of 15 fields (randomly selected as described above) were analyzed for each group. Statistical analysis of differences was performed using unpaired Student's t-test. $\mathrm{P}<0.01$ was considered to indicate a statistically significant difference.

\section{Results}

Histopathology results. There were no notable changes in the $\mathrm{H} \& \mathrm{E}$ stained lung sections in rats in the $\mathrm{C}$ group. In the lung sections from the $\mathrm{R}$ group, widespread distortion of the architecture with thickening of the alveolar wall and interstitium, and infiltration of mononuclear cells were observed, which suggests the presence of inflammatory and fibroproliferative change. The same findings noted in the $\mathrm{R}$ group were observed in lung sections from the $\mathrm{R}+\mathrm{T}$ group, but the severity of these changes in the $\mathrm{R}+\mathrm{T}$ group was reduced when compared with that of the $\mathrm{R}$ group (Fig. 2).

TGF- $\beta$ expression, myofibroblast proliferation and immune cell infiltration. The numbers of TGF- $\beta$-expressing cells within a field in the $\mathrm{C}, \mathrm{R}$ and $\mathrm{R}+\mathrm{T}$ groups were $0.5 \pm 0.7,16.7 \pm 6.5$ and $8.0 \pm 2.9$ [mean \pm standard deviation (SD)], respectively (Fig. 3A). No marked differences regarding TGF- $\beta$ expression were observed in the lungs of the $\mathrm{C}$ group, and definitive 
A

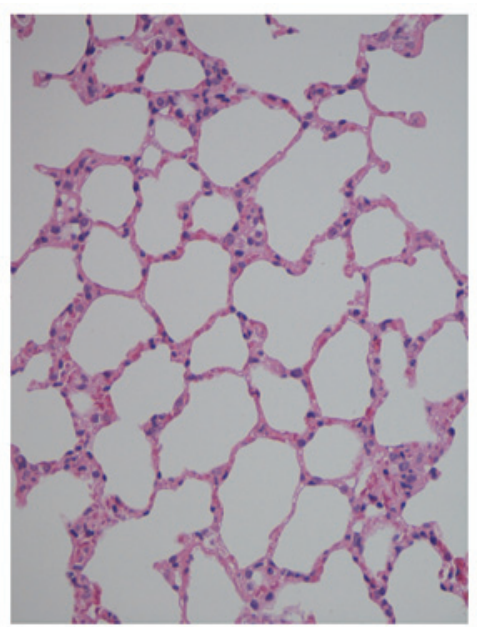

B

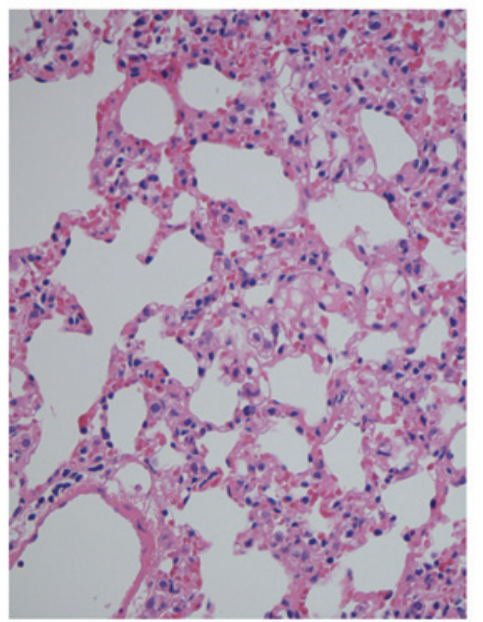

C

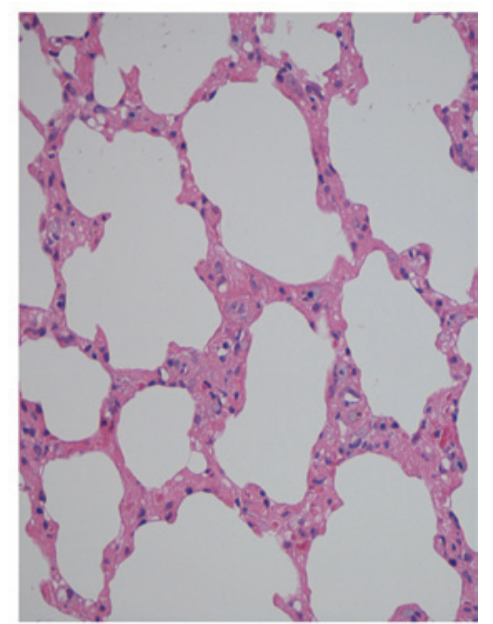

Figure 2. Hematoxylin and eosin stained sections of the lungs at 16 weeks following irradiation ( 8 weeks following single infusion). (A) $\mathrm{C}$ group (control), (B) $\mathrm{R}$ group (radiation plus saline) and (C) $\mathrm{R}+\mathrm{T}$ group (radiation plus soluble transforming growth factor- $\beta$ type II receptor). Magnification, $\mathrm{x} 200$.

A

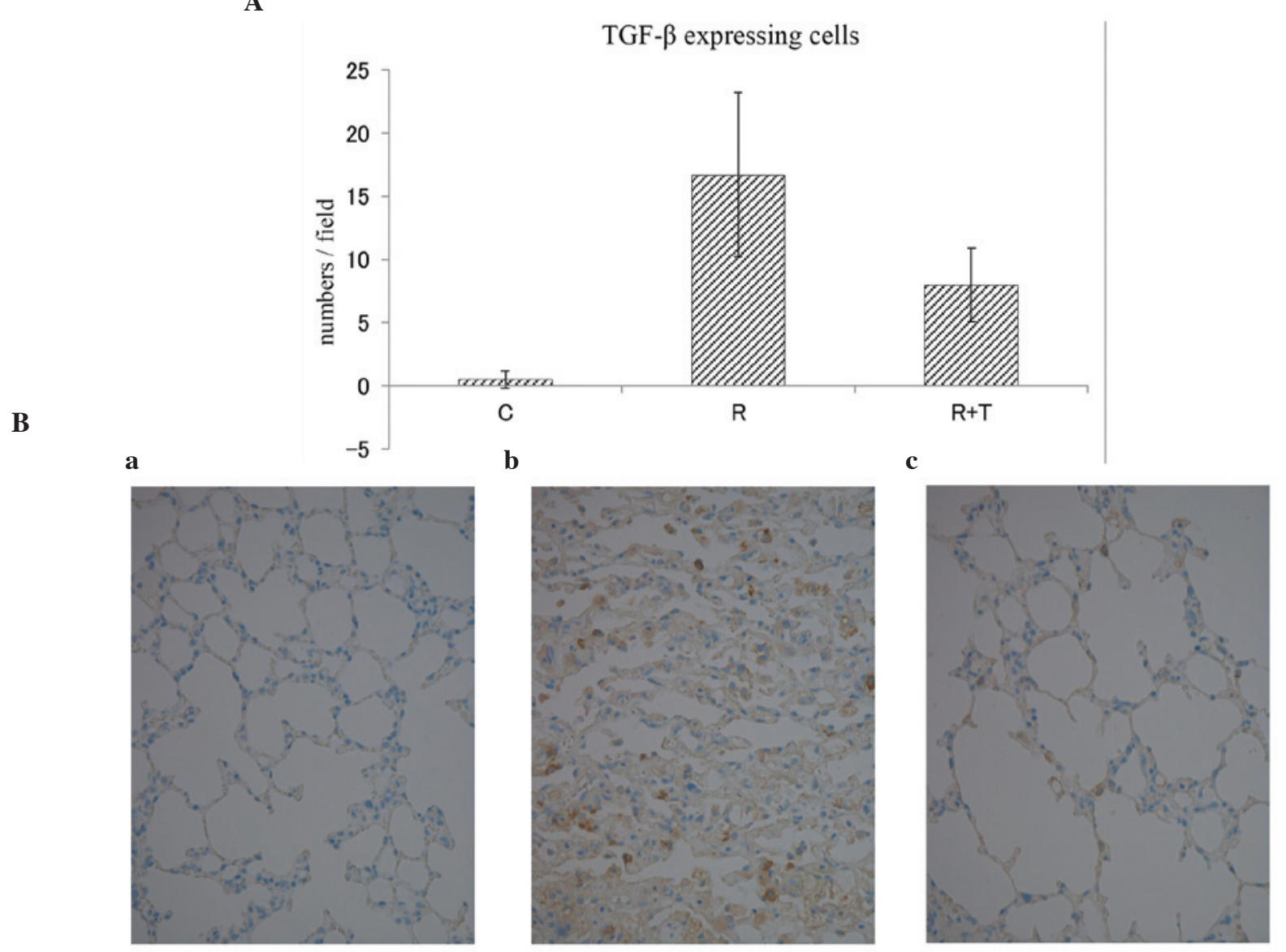

Figure 3. (A) The numbers of TGF- $\beta$-expressing cells within a field in the $C, R$ and $R+T$ groups (mean \pm standard deviation). (B) TGF- $\beta$ expression in the lungs at 16 weeks following irradiation ( 8 weeks following single infusion); (B-a) $\mathrm{C}$ group, (B-b) R group and (B-c) $\mathrm{R}+\mathrm{T}$ group (magnification, $\mathrm{x} 200$ ). TGF- $\beta$, transforming growth factor- $\beta$; $C$, control; $R$, radiation plus saline; $R+T$, radiation plus soluble TGF- $\beta$ type II receptor.

TGF- $\beta$ expression was observed in the lungs of the $\mathrm{R}$ group. By contrast, in the lungs of the $\mathrm{R}+\mathrm{T}$ group, TGF- $\beta$ expression was significantly lower than in the R group (Fig. 3B). The numbers of proliferating myofibroblasts within a field in the $\mathrm{C}, \mathrm{R}$ and $\mathrm{R}+\mathrm{T}$ groups were $1.1 \pm 1.3,12.7 \pm 9.8$ and $3.5 \pm 2.9$ (mean $\pm \mathrm{SD}$ ), respectively (Fig. 4). The numbers of infiltrating macrophages/monocytes within a field in the $\mathrm{C}, \mathrm{R}$ and $\mathrm{R}+\mathrm{T}$ groups were $2.0 \pm 1.7,9.5 \pm 4.4$ and $4.1 \pm 4.0$ (mean $\pm \mathrm{SD}$ ), respectively (Fig. 5). The findings for myofibroblast proliferation and macrophage/monocyte infiltration were identical to those for TGF- $\beta$ expression in the lungs of each group. With respect to fibroproliferation, $4.5 \pm 1.0 \%$ (mean $\pm \mathrm{SD}$ ) of the total area of 


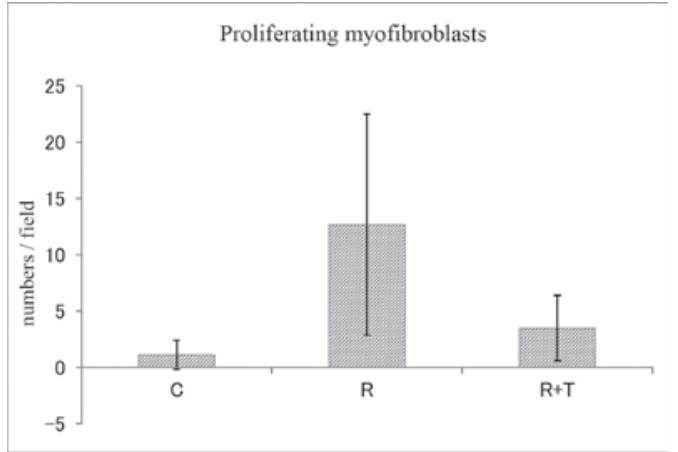

Figure 4. Numbers of proliferating myofibroblasts within a field in the $\mathrm{C}, \mathrm{R}$ and $\mathrm{R}+\mathrm{T}$ groups (mean \pm standard deviation). $\mathrm{C}$, control; $\mathrm{R}$, radiation plus saline; $\mathrm{R}+\mathrm{T}$, radiation plus soluble transforming growth factor- $\beta$ type II receptor.

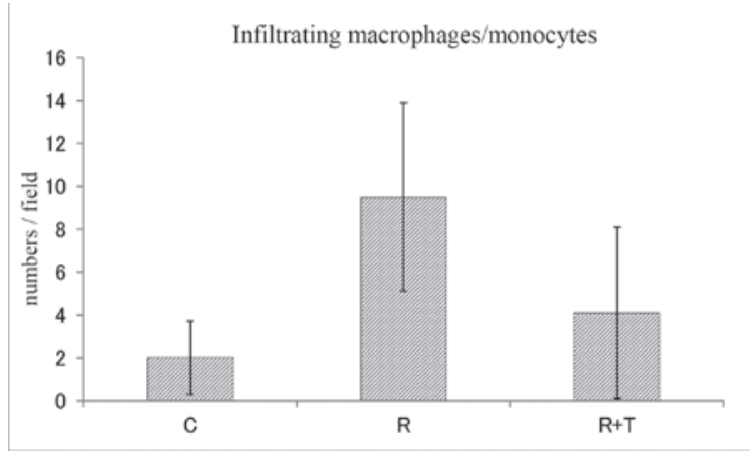

Figure 5. Numbers of infiltrating macrophages/monocytes within a field in the $\mathrm{C}, \mathrm{R}$ and $\mathrm{R}+\mathrm{T}$ groups (mean \pm standard deviation). $\mathrm{C}$, control; $\mathrm{R}$, radiation plus saline; $\mathrm{R}+\mathrm{T}$, radiation plus soluble transforming growth factor- $\beta$ type II receptor.

the sections was stained red in the $\mathrm{C}$ group. In the $\mathrm{R}$ group, $19.8 \pm 4.3 \%$ were stained red. The red-stained area in the $\mathrm{R}+\mathrm{T}$ group was $10.0 \pm 5.7 \%$, which was markedly lower than that in the R group (Fig. 6A and B).

\section{Discussion}

For the management of radiation-induced fibroproliferative changes, numerous drugs have been investigated in experimental studies and clinical trials. These include anti-inflammatory agents, such as steroids, drugs acting on blood flow, interferons and superoxide dismutases (SODs). A number of these were found to be effective for the prevention and treatment of radiation-induced fibroproliferation. Using a porcine model, Lefaix et al (10) demonstrated that pentoxifylline combined with $\alpha$-tocopherol is effective for the treatment of fibrotic scar tissue development following exposure to $\gamma$-rays. Delanian et al (11) revealed that liposomal $\mathrm{Cu} / \mathrm{Zn} \mathrm{SOD}$ is clinically effective in reducing long-standing radiation-induced fibrosis. Lefaix et al (12) also reported the effectiveness of $\mathrm{Cu} / \mathrm{Zn}$ - or $\mathrm{Mn}-\mathrm{SOD}$ for the reduction of radiation-induced fibrosis in pigs. Gauter-Fleckenstein et al (13) identified that Mn porphyrin [MnTE-2-PyP(5+)] was able to reverse lung damage when treatment was initiated 8 weeks post-irradiation, at the time of lung injury establishment, with thickening of the alveolar wall and interstitium, and infiltration of mononuclear cells.
$\mathbf{A}$

Red-stained area
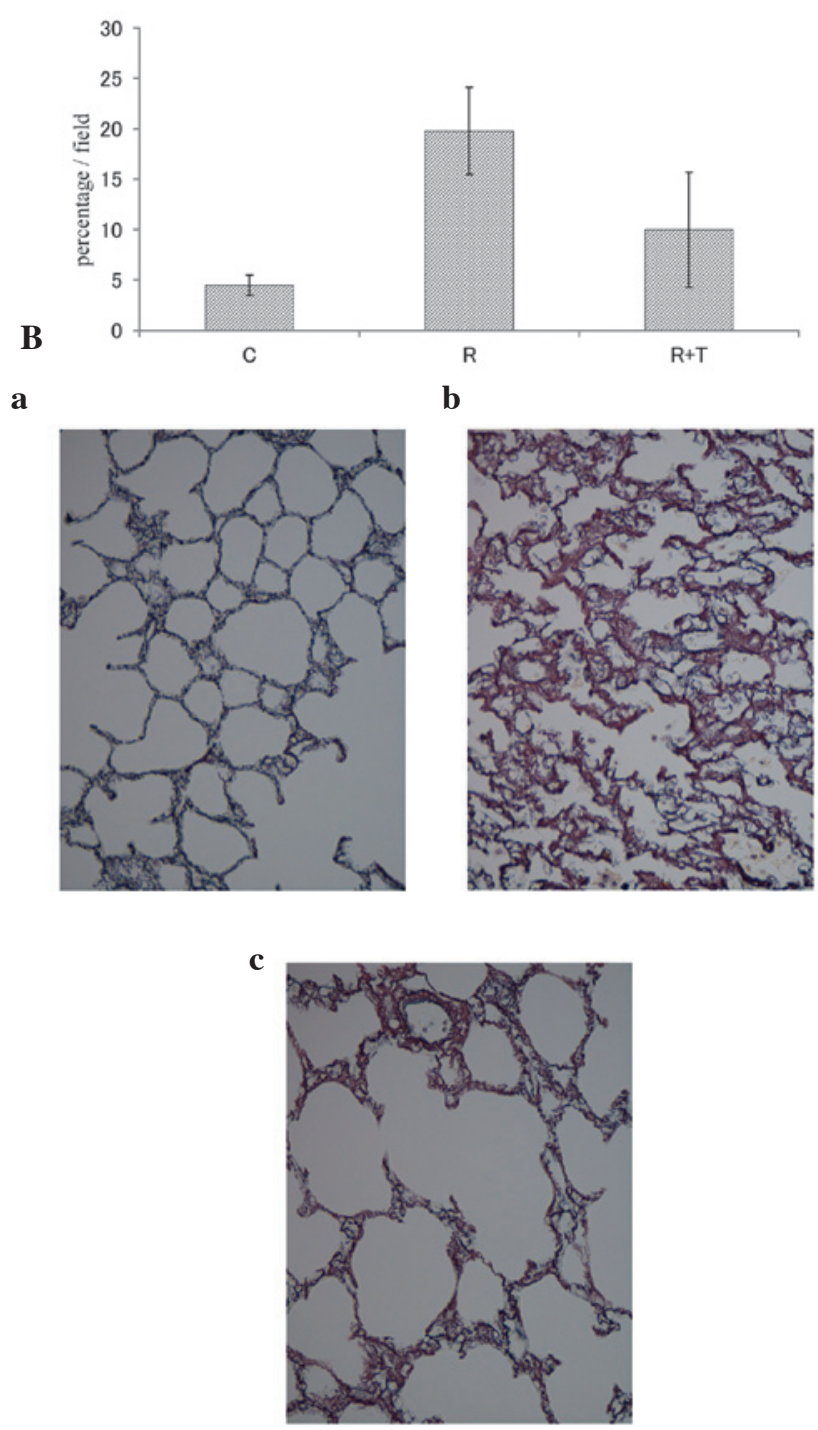

Figure 6. (A) Percentage of red-stained area within a field in the C, R and $\mathrm{R}+\mathrm{T}$ groups (mean \pm standard deviation). (B) Silver staining of the lungs at 16 weeks following irradiation ( 8 weeks following single infusion). (B-a) $\mathrm{C}$ group, (B-b) $\mathrm{R}$ group and (B-c) $\mathrm{R}+\mathrm{T}$ group (magnification, $\mathrm{x} 200$ ). $\mathrm{C}$, control; $\mathrm{R}$, radiation plus saline; $\mathrm{R}+\mathrm{T}$, radiation plus soluble transforming growth factor- $\beta$ type II receptor.

Based on the recent findings on the molecular mechanisms of radiation-induced fibroproliferation, a number of attempts have also been made to prevent radiation-induced fibroproliferative changes in the lung via direct inhibition of TGF- $\beta$ function. Rabbani et al (14) demonstrated the ability of adenovirus-mediated soluble TGF- $\beta$ receptor gene therapy in preventing radiation-induced lung injury. As mentioned above, the usefulness of adenovirus-mediated soluble TGF- $\beta$ type II receptor to ameliorate active TGF- $\beta$ expression and to prevent radiation-induced pulmonary fibroproliferation was also reported (7). Anscher et al $(15,16)$ demonstrated that the anti-TGF- $\beta$ antibody or small molecular inhibitor of TGF- $\beta$ ameliorates radiation-induced lung injury. To date, however, few attempts have been made to reduce established pulmonary fibroproliferative changes by radiation via direct inhibition of TGF- $\beta$ function. 
In the present study, it was demonstrated that TGF- $\beta$ expression, myofibroblast proliferation, macrophage/monocyte infiltration and fibroproliferation in the irradiated lungs of rats were markedly elevated at 16 weeks following irradiation. It was also demonstrated that these markers were significantly reduced by treatment with an adenoviral vector (AdT $\beta$-ExR) expressing a soluble TGF- $\beta$ type II receptor at 8 weeks following irradiation, when marked TGF- $\beta$ expression, myofibroblast proliferation, macrophage/monocyte infiltration and fibroproliferation were observed in 30-Gy irradiated lungs in the control rats. The present data indicates that TGF- $\beta$ has a critical role in the fibroproliferative changes in the irradiated lung, and that the fibroproliferative changes induced by radiation may be reversible. The present results suggest that gene therapy with an adenoviral vector expressing a soluble TGF- $\beta$ receptor is effective in reducing the established pulmonary fibrosis caused by radiation.

However, the present study only confirmed the ability of the adenovirus-mediated soluble TGF- $\beta$ receptor to reduce radiation-induced pulmonary fibroproliferation at a histopathological level. Therefore, whether direct inhibition of TGF- $\beta$ functions by an adenovirus-mediated soluble TGF- $\beta$ receptor actually preserves respiratory function in irradiated lungs requires further investigation. In addition, although it was confirmed that the adenoviral vector itself does not affect the general condition, behavior or macroscopic appearance of the vital organs for at least three months following injection, possible long-term side-effects of TGF- $\beta$ inhibition, such as carcinogenesis, should also be carefully examined in future studies. If AdT $\beta$-ExR is to be used in gene therapy, efforts to optimize administration methods and to minimize side effects directly associated with the use of adenoviral vectors are also required (17).

\section{References}

1. Gabbiani G: Modulation of fibroblastic cytoskeletal features during wound healing and fibrosis. Pathol Res Pract 190: 851-853, 1994

2. Desmoulière A: Factors influencing myofibroblast differentiation during wound healing and fibrosis. Cell Biol Int 19: 471-476, 1995.

3. Powell DW, Mifflin RC, Valentich JD, et al: Myofibroblasts. I. Paracrine cells important in health and disease. Am J Physiol 277: C1-9, 1999.
4. Finkelstein JN, Johnston CJ, Baggs R, et al: Early alterations in extracellular matrix and transforming growth factor $\beta$ gene expression in mouse lung indicative of late radiation fibrosis. Int J Radiat Oncol Biol Phys 28: 621-631, 1994.

5. Yi ES, Bedoya A, Lee $\mathrm{H}$, et al: Radiation-induced lung injury in vivo: Expression of transforming growth factor-beta precedes fibrosis. Inflammation 20: 339-352, 1996.

6. Franko AJ, Sharplin J, Ghahary A, et al: Immunohistochemical localization of transforming growth factor $\beta$ and tumor necrosis factor $\alpha$ in the lungs of fibrosis-prone and 'non-fibrosing' mice during the latent period and early phase after irradiation. Radiat Res 147: 245-256, 1997.

7. Nishioka A, Ogawa Y, Mima T, et al: Histopathologic amelioration of fibroproliferative change in rat irradiated lung using soluble transforming growth factor-beta (TGF- $\beta$ ) receptor mediated by adenoviral vector. Int J Radiat Oncol Biol Phys 58: 1235-1241, 2004.

8. Sakamoto T, Ueno H, Sonoda KH, et al: Blockade of TGF-beta by in vivo gene transfer of a soluble TGF-beta type II receptor in the muscle inhibits corneal opacification, edema and angiogenesis. Gene Ther 7: 1915-1924, 2000.

9. Ueno H, Sakamoto T, Nakamura T, et al: A soluble transforming growth factor-beta receptor expressed in muscle prevents liver fibrogenesis and dysfunction in rats. Hum Gene Ther 11: 33-42, 2000.

10. Lefaix JL, Delanian S, Vozenin MC, et al: Striking regression of subcutaneous fibrosis induced by high doses of gamma rays using a combination of pentoxifylline and alpha-tocopherol: an experimental study. Int J Radiat Oncol Biol Phys 43: 839-847, 1999.

11. Delanian S, Baillet F, Huart J, et al: Successful treatment of radiation-induced fibrosis using liposomal $\mathrm{Cu} / \mathrm{Zn}$ superoxide dismutase: clinical trial. Radiother Oncol 32: 12-20, 1994.

12. Lefaix JL, Delanian S, Leplat JJ, et al: Successful treatment of radiation-induced fibrosis using $\mathrm{Cu} / \mathrm{Zn}-\mathrm{SOD}$ and $\mathrm{Mn}-\mathrm{SOD}$ : An experimental study. Int J Radiat Oncol Biol Phys 35: 305-312, 1996.

13. Gauter-Fleckenstein B, Fleckenstein K, Owzar K, et al: Early and late administration of MnTE-2-PyP5 ${ }^{+}$in mitigation and treatment of radiation-induced lung damage. Free Radic Biol Med 48: 1034-1043, 2010.

14. Rabbani ZN, Anscher MS, Zhang X, et al: Soluble TGFbeta type II receptor gene therapy ameliorates acute radiation-induced pulmonary injury in rats. Int J Radiat Oncol Biol Phys 57: 563-572, 2003.

15. Anscher MS, Thrasher B, Rabbani Z, et al: Antitransforming growth factor-beta antibody 1D11 ameliorates normal tissue damage caused by high-dose radiation. Int J Radiat Oncol Biol Phys 65: 876-881, 2006

16. Anscher MS, Thrasher B, Zgonjanin L, et al: Small molecular inhibitor of transforming growth factor-beta protects against development of radiation-induced lung injury. Int J Radiat Oncol Biol Phys 71: 829-837, 2008.

17. Nishioka A, Ogawa Y and Ueno H: In response to Drs. Ubrovskaya and Chukhlovin. Re: Histopathologic amelioration of fibroproliferative change in rat irradiated lung using soluble transforming growth factor-beta (TGF-beta) receptor mediated by adenoviral vector. Int J Radiat Oncol Biol Phys 61: 308-309, 2005. 